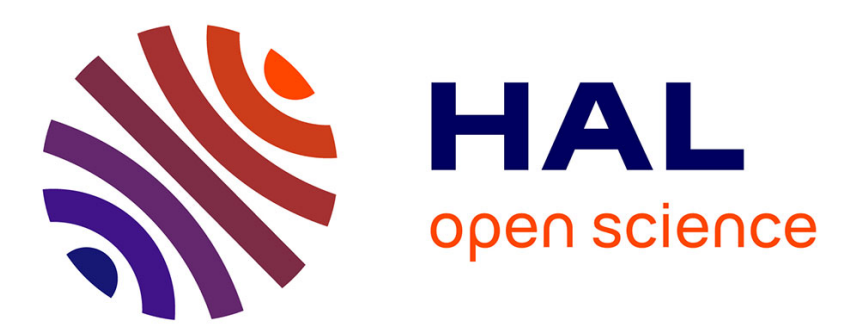

\title{
Ethnic differences in Rotterdam criteria and metabolic risk factors in a multiethnic group of women with PCOS studied in Denmark
}

Dorte Glintborg, Hanne Mumm, David Hougaard, Pernille Ravn, Marianne Andersen

\section{To cite this version:}

Dorte Glintborg, Hanne Mumm, David Hougaard, Pernille Ravn, Marianne Andersen. Ethnic differences in Rotterdam criteria and metabolic risk factors in a multiethnic group of women with PCOS studied in Denmark. Clinical Endocrinology, 2010, 73 (6), pp.732. 10.1111/j.1365-2265.2010.03873.x . hal-00593443

\section{HAL Id: hal-00593443 \\ https://hal.science/hal-00593443}

Submitted on 16 May 2011

HAL is a multi-disciplinary open access archive for the deposit and dissemination of scientific research documents, whether they are published or not. The documents may come from teaching and research institutions in France or abroad, or from public or private research centers.
L'archive ouverte pluridisciplinaire HAL, est destinée au dépôt et à la diffusion de documents scientifiques de niveau recherche, publiés ou non, émanant des établissements d'enseignement et de recherche français ou étrangers, des laboratoires publics ou privés. 


\section{CLINICAL ENDOCRINOLOGY}

\section{Ethnic differences in Rotterdam criteria and metabolic risk factors in a multiethnic group of women with PCOS studied in Denmark}

\begin{tabular}{|r|l|}
\hline Journal: & Clinical Endocrinology \\
\hline Manuscript ID: & CEN-2010-000373.R2 \\
\hline Manuscript Type/Office: & 1 Original Article - UK/Europe \\
\hline Date Submitted by the \\
Author: & 16-Aug-2010 \\
\hline Complete List of Authors: & $\begin{array}{l}\text { Glintborg, Dorte; Odense University Hospital, Endocrinology and } \\
\text { Metabolism } \\
\text { Mumm, Hanne; Odense University Hospital, Endocrinology and } \\
\text { Metabolism } \\
\text { Hougaard, David; Statens Serum Institut, Statens Serum Institut } \\
\text { Ravn, Pernille; Odense University Hospital, Department of } \\
\text { Gynecology and Obstetrics } \\
\text { Andersen, Marianne; Odense University Hospital, Endocrinology and } \\
\text { Metabolism }\end{array}$ \\
\hline Key Words: & $\begin{array}{l}\text { Hirsutism < Conditions: < Ovary, Polycystic ovary syndrome < } \\
\text { Conditions: < Ovary, Insulin resistance < Conditions: < } \\
\text { Obesity/Lipids/Nutrition, Obesity, morbid < Conditions: < } \\
\text { Obesity/Lipids/Nutrition }\end{array}$ \\
\hline \hline
\end{tabular}

\section{SCHOLARONE Manuscripts}


Authors:

Dorte Glintborg MD, PhD (1)

Hanne Mumm MD (1)

David Hougaard MD (3)

Pernille Ravn MD, Dr Med (2)

Marianne Andersen MD, $\mathrm{PhD}(1)$

1. Department of Endocrinology and Metabolism, Odense University Hospital, 5000 Odense C, Denmark.

2. Department of Gynecology and Obstetrics, Odense University Hospital, 5000 Odense C, Denmark. 5000 Odense C, Denmark.

3. Statens Serum Institut, 2300 Copenhagen S, Denmark

Corresponding author: Dorte Glintborg, Kløvervænget 6, 3rd floor, 5000 Odense C. d.glintborg@gmail.com Fax: 004566113371.

Acknowledgements: The authors have no conflicts of interest

Keywords: oral glucose tolerance test, insulin resistance, diabetes, ACTH test, ethnicity, Caucasian

Word count: 2948 


\begin{abstract}
Objective: Clinical manifestations and metabolic risk factors may differ in ethnic subgroups of patients with PCOS.

Design: Retrospective trans-sectional study.

Patients: 1002 premenopausal women with the diagnoses hirsutism or PCOS were divided according to ethnicity: Caucasian (CA, n=784), Middle East (ME, n=190), Asian ( $n=14)$, other ( $n=14)$.

Measurements: Clinical evaluation (hirsutism, BMI, waist, blood pressure), hormone analyses (testosterone, sex hormone binding globulin, prolactin, lipids, insulin, glucose), and transvaginal ultrasound. Oral glucose tolerance tests (OGTT) $(n=499)$ and ACTH tests $(n=434)$ were performed in a subgroup of patients.
\end{abstract}

Results (CA vs. ME women): CA women were older [32(25-37) vs. 25(18-32) years, median (quartiles)] and had increased BMI compared to ME women. After correcting for age and BMI CA women were less hirsute, but had increased testosterone levels compared to ME women. The Rotterdam criteria were fulfilled in $56 \%$ of both populations but PCO was diagnosed in $47 \%$ CA vs. $29 \%$ ME women, $p<0.01$. CA women had increased blood pressure and smoked at a higher frequency (40 vs. 23\%), whereas area under the curve for insulin during OGTT was decreased, all $\mathrm{p}<0.001$. Prolactin levels were significantly lower in CA women compared to ME women [7(5-10) vs. 9(6-12) $\mu \mathrm{g} / \mathrm{l}]$ and were inversely associated with smoking status.

Conclusion: CA women had a more adverse cardiovascular profile than ME women, whereas insulin sensitivity was higher. The prevalence of the individual Rotterdam criteria differed significantly in the two study populations. 


\section{Introduction}

Hirsutism affects $10 \%$ females in reproductive age and is caused by increased androgenicity in the pilosebacceus gland (1). Hirsutism is the result of high androgen concentrations often in combination with increased androgen sensitivity (2). Hirsutism is most often caused by polycystic ovary syndrome (PCOS) or idiopathic hirsutism $(\mathrm{IH})$, whereas less than $5 \%$ hirsute patients are diagnosed with rare endocrine disorders (3). PCOS can be defined according to the Rotterdam criteria: 1. Irregular/no ovulations, 2.

Clinical/biochemical hyperandrogenaemia, and 3. Polycystic ovaries (4). Two out of the three criteria need to be fulfilled and other causes of hyperandrogenaemia should be excluded. In contrast, the previously used PCOS criteria as suggested by the National Institute of Health (NIH) include only the first two criteria: Irregular/no ovulations and clinical/biochemical hyperandrogenaemia. The manifestations of PCOS may differ among different ethnic populations (5). It is recognized that Asian women are rarely hirsute (5). The enzyme $5 \alpha$-reductase is responsible for the conversion of testosterone to the more potent androgen dihydrotesterone (DHT) (1). Inherited variations in $5 \alpha$-reductase activity may explain differences in the prevalence of hirsutism among diverse ethnic populations. Individual variations in dermal $5 \alpha$-reductase activity may furthermore explain why hirsute patients often have near-normal testosterone levels and that testosterone levels are poorly associated with clinical hirsute manifestations (1). We are not aware of previous studies reporting differences of the individual diagnostic criteria between different ethnic populations with PCOS.

PCOS and IH is characterized by hyper-inflammation and is associated with insulin resistance and increased risk for cardiovascular disease and diabetes $(6 ; 7)$. It is therefore recommended that PCOS patients are screened for the metabolic syndrome and cardiovascular risk factors $(6 ; 7)$. The metabolic disturbances of PCOS seem to be more pronounced in hyperandrogen patients compared to patients with no hyperandrogenaemia (8). The prevalence of metabolic and cardiovascular risk factors may furthermore vary in different ethnic populations with PCOS. Several studies documented that immigrants in western countries may be at increased risk for life style diseases such as obesity and diabetes (9). Increased risk for diseases 
may be attributable to genetic predisposition or to environmental influences such as different exercise or eating habits. It remains to be documented whether some ethnic PCOS populations are at increased risk for diabetes and therefore need closer follow up. In addition, some ethnic subgroups may be relatively protected against the long term side effects of PCOS.

Prolactin levels are routinely measured in hirsute patients to exclude prolactinomas as a cause of menstrual irregularity. Increased prolactin levels could be associated with irregular menses, but we are not aware of previous studies evaluating associations between prolactin and manifestations of PCOS in population studies.

The aim of the present study was to evaluate differences in clinical manifestations, metabolic risk factors, and diabetes risk in a multiethnic group of women with PCOS studied in Denmark 


\begin{abstract}
Material
Inclusion criteria: All premenopausal women referred to the outpatient clinic at the Department of Endocrinology during $1997-2008$ with the referral diagnoses hirsutism and/or PCOS were included. The patients should fulfill the Rotterdam criteria for PCOS or have clinical/biochemical hyperandrogenemia. As part of the clinical practice protocol of the department patients suspended oral contraceptives for at least three months prior to evaluation and metformin treatment was paused for at least one month prior to evaluation. Seventeen patients in the study population were on antihypertensive treatment. All included patients had normal thyroid function. All presented data are pretreatment values.

Exclusion criteria: Women younger than 15 years were referred to the department of Pediatrics at Odense University Hospital and patients with a primary complaint of infertility were referred to the local Fertility Clinic. Patients not attending for the measurement of hormonal or metabolic parameters were excluded. Patients with serious endocrine diseases were excluded as previously described (3). The study was designed as a retrospective observational audit and we did therefore not search for approval from the local Ethics Committee.
\end{abstract}

\author{
Methods \\ Routine evaluation included medical history, clinical examination, transvaginal ultrasound (US), and fasting \\ blood samples.
}

Medical history: Cycle history was recorded in all patients using a standard scheme prepared for hirsute patients. Ancestry was recorded by using an evaluation scheme where the doctor marked the patient as originating from Caucasia, Middle East, Africa or Asia and the country of origin was specified. In few cases the originating country was not specified in the patient reports (Table 1). Only patients where both parents originated from the same continent were included in the study population. All participating patients were first or second generation immigrants. Marital status was not routinely recorded.

Clinical evaluation: Hirsutism was assessed by the Ferriman Gallwey score (10). Waist circumference was measured to the nearest $\mathrm{cm}$ in a standing position midway between the lower costal margin and the iliac crest. The BMI was calculated as the weight in kilograms divided by the square height in meters. 
Transvaginal US were performed at the Department of Gynecology, Odense University Hospital and polycystic ovaries were defined according to Adams (11). Ovarian volume was not routinely measured in the present study. All patients were offered transvaginal US but a small group of patients did not attend for the examination. Transvaginal US was performed in 840/974 patients.

Blood samples: Fasting blood samples was drawn during the morning in follicular phase (cycle days 2-8) in patients with a cycle length shorter than three months, patients with cycle length $>3$ months had the blood samples drawn on a random cycle day. Blood tests included androgens (total testosterone, free-testosterone, sex hormone binding globulin (SHBG), dehydroepiandrosterone sulfate (DHEAS), 17-hydroxyprogesterone (17OHP)), LH, FSH, prolactin, and lipid profile.

During 1997-2002 patients routinely underwent OGTT and ACTH tests. These data on Caucasian patients have previously been published (3;12). During 2002- 2009 OGTT were only performed in high risk patients as recommended by international guidelines (13). Similarly, ACTH tests were only performed in patients with increased baseline 17OHP levels as previously discussed (12).

The $0.25 \mathrm{mg}$ ACTH test (Synachten $0.25 \mathrm{mg} / \mathrm{ml}$, Novartis Healthcare, Copenhagen, Denmark) was performed between $08.00 \mathrm{~h}$ and $10.00 \mathrm{~h}$ during follicular phase. Cortisol and 17OHP were measured at baseline and at 30 and $60 \mathrm{~min}$. ACTH tests were performed in 434 individuals (1997-2002, n=416). OGTT was performed at 08.00 on a random day of the cycle. Insulin, C-peptide, and capillary blood glucose (CBG) were measured at baseline and at 30,60, and 120 minutes after oral ingestion of $75 \mathrm{~g}$ glucose dissolved in water. OGTT was performed in 499 patients $(1997-2003, n=390)$ excluding 33 patients with an established diabetes diagnosis.

\footnotetext{
Assays

LH, FSH, cortisol, insulin, and C-peptide were analyzed by time-resolved flouroimmunoassay using commercial kits (AutoDELFIA, Wallac Oy, Turku, Finland). Intra-assay variations were: FSH 1.0 - 1.4\%, LH 1.8 - 9.4\%, cortisol $2.7-3.6 \%$, insulin $2.1-3.7 \%$, and C-peptide $3.1-5.0 \%$. Inter- assay variations were: FSH 2.1 - 3.7\%, LH 2.0 - 3.9\%, cortisol 0.8 - 1.9\%, insulin $3.4-4.0 \%$, and C-peptide 1.9 - 3.0\%.
} 


\section{Statistic methods}

All presented data represent pre-treatment values. Pakistan is most often referred to as part of the South Asian continent but may according to recent definitions also be included as part of the Middle East. Due to the limited number of subjects we chose to omit Asian patients. In order not to exclude the 14 patients from Pakistan we included these patients as part of the Middle Eastern patient group. Omitting the 14 Pakistani women from the calculations did not change the significant differences between ME and CA patients. Blood pressures measured in patients using antihypertensive treatment were not included in the dataset. Most parameters were not normally distributed and were therefore described using medians and quartiles. The Mann Whitney test was used to compare differences between two groups. The Chi squared test was used to test for differences in frequencies between groups. 
We performed multiple regression analyses to take into account that the two study populations differed significantly in age and BMI. These analyses were performed on log data. In regression analyses metabolic and clinical characteristics were entered as the dependent variable and age, BMI, and ethnicity (Caucasian $=1$, Middle East $=2$ ) were entered as the explanatory variables. In tables, p-values for the relevant explanatory variable are presented. We used SPSS version 13 (SPSS, Chicago, IL) in our calculations. Pvalues $<0.05$ were considered significant.

\section{Results}

\section{Clinical and biochemical characteristics}

1206 patients were referred for evaluation. 1002 patients fulfilled the inclusion criteria and 204 patients were excluded. Table 1 shows the geographic distribution of included patients. The patients were divided according to ethnicity: Caucasian (CA, n=784), Middle East (ME, n=190), Asian ( $n=14)$, various ( $n=14)$. Table 2 presents clinical and biochemical characteristics in CA and ME patients. CA patients were significantly older and had higher BMI compared to ME patients. After correcting for differences in age and BMI between the two study populations, clinical hyperandrogenicity was lower in CA women and SHBG and androgen levels were higher. Prolactin levels were lower in CA women. CA women had increased blood pressure and smoking prevalence, but no significant differences were found in lipid profiles (Table 2, Figure 1). The risk of diabetes and IGT was comparable in the two study populations, but CA women had decreased AUC insulin and 2 hour glucose during OGTT and decreased frequency of high fasting insulin (Table 3). Basal 17OHP was increased in CA women but no significant differences were detected in adrenal activity during ACTH tests.

\section{PCOS criteria}

Rotterdam criteria: A total of 557 patients fulfilled the Rotterdam criteria for PCOS: $56.2 \%$ (448/784) CA vs. 56.8\% (109/190) ME women. The prevalence of the individual criteria differed significantly between the two study populations, Figure 1. 47.0\% (314/668) CA women vs. 29.0\% (50/172) ME women had PCO and $89.1 \%(699 / 684)$ vs. $93.2 \%$ (179/190) had clinical and/or biochemical hyperandrogenism (both $\mathrm{p}<0.05)$.

Table 4 presents clinical and biochemical characteristics of the 557 patients fulfilling the Rotterdam criteria 
divided according to BMI. Overweight patients were significantly more insulin resistant and had a more adverse cardiovascular risk profile than normal weight patients within both ethnic subgroups of patients. The different prevalence of hyperandrogenism and PCO remained significant between CA and ME women fulfilling the Rotterdam criteria (data not shown).

NIH criteria: The NIH criteria were fulfilled in 439 patients, 44.5\% (349/784) CA vs. 47.3\% (90/190) ME women. Differences in metabolic and hormonal parameters between CA and ME women were not significantly affected when NIH criteria were applied instead of the Rotterdam criteria (data not shown). Idiopathic hirsutism defined as regular menses, testosterone levels within reference interval and US with normal ovaries was diagnosed in 232 patients (CA n=183, ME n=49).

\section{Multiple regression analysis}

Ethnicity as an independent predictor of testosterone levels and metabolic risk factors is shown in Table $\mathbf{5 .}$ ME women had increased AUC insulin and $2 \mathrm{~h}$ glucose and decreased androgen and SHBG levels after correcting for BMI and age.

Multiple regression analyses were performed as described above with prolactin entered as the dependent variable. HDL $(B=0.21, p=0.03), \operatorname{LDL}(B=-0.17, p=0.02), 170 H P 0(B=0.12, p=0.004)$, and smoking status $(B=-0.05, p=0.007)$ were independent predictors of prolactin levels after correcting for ethnicity, age, and BMI. Prolactin levels were 7(5-10) vs. 6(5-9) $\mu \mathrm{g} / \mathrm{l}$ in non-smoking vs. smoking patients $(\mathrm{p}<0.001)$. No significant associations were found between prolactin and sex hormones, cycle history, or PCO status. 


\section{Discussion}

Limited data are available on ethnic differences in the manifestations of PCOS in North European study populations. In the present study we included data from a large well characterized Danish population of premenopausal PCOS women. CA women were significantly older than ME women and had significantly higher BMI. After correcting for differences in age and BMI, ME women were characterized by increased androgenicity, which could be explained by decreased SHBG, and increased diabetes risk whereas a more unfavourable cardiovascular risk profile was found in CA women.

It has been reported that African-American and Hispanic women with PCOS are more insulin resistant and have increased diabetes risk compared to Caucasian women $(5 ; 16)$. Our findings of increased metabolic risk factors in ME women compared to CA women are in agreement with studies in populations without PCOS $(9 ; 17 ; 18)$, whereas few studies have been performed in PCOS populations. Wijeyaratne et al included 47 south Asian women with PCOS (including 40 women from Pakistan) and 40 Caucasian women with PCOS (19). In agreement with our study, south Asian patients were younger with decreased BMI and increased FGscore compared to Caucasian patients (19). Asian women had significantly decreased insulin sensitivity compared to CA women, whereas no significances were found in fasting glucose levels (19). We and Wijeyaratne et al (19) reported significantly increased SHBG levels in Caucasian women, which may support higher insulin sensitivity (19;20). Sixty-four percent Asian women vs. 30\% Caucasian women with PCOS had a family history of diabetes, which may have affected results (19). The effects of race and family history on diabetes risk were studied by Ehrmann et al in a mixed ethnic study population of 408 PCOS patients of primarily black and white race (16). Ethnicity was found to influence parameters of insulin resistance and body composition independent of family history (16). Intra-family marriages are more prevalent in ME women than in CA women (21). In the present study we did not have data on family marriages. In a Pakistan population of PCOS women, consanguineous marriage was associated with insulin resistance and glucose intolerance and a family history of diabetes and cardiovascular disease was observed more often in the group of women marrying within family (21).

CA women in the present study had increased blood pressure, smoked at a higher frequency, and tended to have a more adverse lipid profile than ME women. These findings suggest that CA women are at increased 
An unexpected finding of the present study was the higher prevalence of polycystic ovaries in CA women compared to ME women. We are not aware of previous studies reporting similar differences in the prevalence of PCO between different ethnic populations with PCOS. In the present study PCO was defined according to the criteria suggested by Adams and ovarian volume was not systematically recorded. The Rotterdam criteria suggest that increased ovarian volume $>10 \mathrm{ml}$ alone can be used to define PCO (4). It is therefore possible that the prevalence of PCO may be higher than estimated in the present study. In the study by Wijeyaratne, there was a trend to increased ovarian volume in Asian PCOS patients, but this did not reach statistical significance (19). Welt et al reported similar prevalence of PCO between Caucasian PCOS patients from Boston and Iceland but Icelandic patients had smaller ovaries with decreased follicle number supporting that ovarian morphology may vary in different study populations (25).

The median age upon referral was relatively high in our study population and CA patients were seven years older than ME women. Patients with a primary wish for conception were referred directly to the fertility 
clinic and therefore the primary complaints of our population were irregular menses and hirsutism. The median age for first child birth in Denmark is 29-30 years and more than 25\% women in reproductive age use oral contraceptives (OC) (26). OC pills efficiently alleviate the symptoms of PCOS and this may explain the relatively high age upon referral in our population. It is possible that a lesser percentage of ME women use OC as birth control and therefore the symptoms of PCOS present in an earlier age. Impaired quality of life due to for example overweight and hirsutism is well described in PCOS and may be the primary reason for referral of the patient (27). In a previous Austrian study, quality of life regarding infertility, overweight, hirsutism, and menstrual disturbances were significantly impaired in infertile Moslem immigrant women with PCOS compared to Austrian women with comparable clinical or biochemical symptoms of PCOS (28).

Prolactin levels were routinely measured to exclude prolactinomas as a cause of menstrual irregularity and none of the included patients had prolactin levels above reference interval. To our knowledge we are the first to report increased prolactin levels in ME patients compared to CA patients. Multiple regression analyses suggested that the difference could in part be explained by decreased smoking prevalence in ME women. Increased prolactin levels were furthermore associated with increased HDL, decreased TG and increased 17OHP levels after correcting for BMI, race, and age. Our findings are in agreement with previous studies on the effect of nicotine on prolactin (29;30). We are not aware of previous studies documenting associations between prolactin secretion and lipid metabolism. Further studies are needed to evaluate prolactin levels among different ethnic populations with PCOS.

The present study included patients referred to our specialist center from general practitioners and local gynecologists and dermatologists. The evaluated patient population therefore probably represents a selected patient population. Furthermore, the ME patient group included patients from a large geographic area. The patients underwent a standardized evaluation program including check schemes to minimize the inter observer variation but clearly more prospective studies are needed to confirm our study results in well characterized PCOS populations of mixed ethnicity. 


\section{Conclusion \\ ME women with PCOS are referred at a younger age and are characterized by decreased BMI and increased androgenicity compared to CA women with PCOS. Insulin resistance is increased in ME women whereas the cardiovascular risk profile is more beneficial regarding blood pressure and smoking status. The present study support that ethnic groups differ in clinical and biochemical presentation of PCOS and future studies should focus on prospective data in different ethnic populations with PCOS.}




\section{Reference List}

1. Azziz R, Carmina E, Sawaya ME. (2000) Idiopathic hirsutism. Endocr Rev, 4, 347-62.

2. Barth JH. (1997) Investigations in the assessment and management of patients with hirsutism. Curr Opin Obstet Gynecol, 3, 187-92.

3. Glintborg D, Henriksen JE, Andersen M, et al. (2004) Prevalence of endocrine diseases and abnormal glucose tolerance tests in 340 Caucasian premenopausal women with hirsutism as the referral diagnosis. Fertil Steril, 6, 1570-9.

4. Revised 2003 consensus on diagnostic criteria and long-term health risks related to polycystic ovary syndrome. (2004) Fertil Steril, 1, 19-25.

5. Huddleston HG, Cedars MI, Sohn SH, et al. (2010) Racial and ethnic disparities in reproductive endocrinology and infertility. Am J Obstet Gynecol, 5, 413-9.

6. Glintborg D, Andersen M. (2010) An update on the pathogenesis, inflammation, and metabolism in hirsutism and polycystic ovary syndrome. Gynecol Endocrinol, 4, 281-96.

7. Wild RA, Carmina E, amanti-Kandarakis E, et al. (2010) Assessment of Cardiovascular Risk and Prevention of Cardiovascular Disease in Women with the Polycystic Ovary Syndrome: A Position Statement by the Androgen Excess and Polycystic Ovary Syndrome (AE-PCOS) Society. J Clin Endocrinol Metab.

8. Azziz R, Carmina E, Dewailly D, et al. (2009) The Androgen Excess and PCOS Society criteria for the polycystic ovary syndrome: the complete task force report. Fertil Steril, 2 , 456-88.

9. Daryani A, Berglund L, Andersson A, et al. (2005) Risk factors for coronary heart disease among immigrant women from Iran and Turkey, compared to women of Swedish ethnicity. Ethn Dis, 2, 213-20.

10. Ferriman D, Gallwey JD. (1961) Clinical assessment of body hair growth in women. J Clin Endocrinol: 1440-7.

11. Adams J, Polson DW, Franks S. (1986) Prevalence of polycystic ovaries in women with anovulation and idiopathic hirsutism. Br Med J (Clin Res Ed), 6543, 355-9.

12. Glintborg D, Hermann AP, Brusgaard K, et al. (2005) Significantly higher adrenocorticotropin-stimulated cortisol and 17-hydroxyprogesterone levels in 337 consecutive, premenopausal, caucasian, hirsute patients compared with healthy controls. $J$ Clin Endocrinol Metab, 3, 1347-53.

13. Salley KE, Wickham EP, Cheang KI, et al. (2007) POSITION STATEMENT: Glucose Intolerance in Polycystic Ovary Syndrome A Position Statement of the Androgen Excess Society. J Clin Endocrinol Metab, 12, 4546-56. 
14. Lykkesfeldt G, Bennett P, Lykkesfeldt AE, et al. (1985) Abnormal androgen and oestrogen metabolism in men with steroid sulphatase deficiency and recessive X-linked ichthyosis. Clin Endocrinol (Oxf), 4, 385-93.

15. Radziuk J. (2000) Insulin sensitivity and its measurement: structural commonalities among the methods. J Clin Endocrinol Metab, 12, 4426-33.

16. Ehrmann DA, Kasza K, Azziz R, et al. (2005) Effects of race and family history of type 2 diabetes on metabolic status of women with polycystic ovary syndrome. J Clin Endocrinol Metab, 1, 66-71.

17. Uitewaal PJ, Manna DR, Bruijnzeels MA, et al. (2004) Prevalence of type 2 diabetes mellitus, other cardiovascular risk factors, and cardiovascular disease in Turkish and Moroccan immigrants in North West Europe: a systematic review. Prev Med, 6, 1068-76.

18. Glans F, Elgzyri T, Shaat N, et al. (2008) Immigrants from the Middle-East have a different form of Type 2 diabetes compared with Swedish patients. Diabet Med, 3, 303-7.

19. Wijeyaratne CN, Balen AH, Barth JH, et al. (2002) Clinical manifestations and insulin resistance (IR) in polycystic ovary syndrome (PCOS) among South Asians and Caucasians: is there a difference? Clin Endocrinol (Oxf), 3, 343-50.

20. Nestler JE. (1993) Sex hormone-binding globulin: a marker for hyperinsulinemia and/or insulin resistance? J Clin Endocrinol Metab, 2, 273-4.

21. Haq F, Rizvi J. (2008) Infertility and polycystic ovarian syndrome: a study of association between body mass index and intrafamily marriages. Gynecol Obstet Invest, 4, 269-74.

22. Lo JC, Feigenbaum SL, Yang J, et al. (2006) Epidemiology and adverse cardiovascular risk profile of diagnosed polycystic ovary syndrome. J Clin Endocrinol Metab, 4, 1357-63.

23. Kumar A, Woods KS, Bartolucci AA, et al. (2005) Prevalence of adrenal androgen excess in patients with the polycystic ovary syndrome (PCOS). Clin Endocrinol (Oxf), 6, 644-9.

24. Kauffman RP, Baker VM, DiMarino P, et al. (2006) Hyperinsulinemia and circulating dehydroepiandrosterone sulfate in white and Mexican American women with polycystic ovary syndrome. Fertil Steril, 4, 1010-6.

25. Welt CK, Arason G, Gudmundsson JA, et al. (2006) Defining constant versus variable phenotypic features of women with polycystic ovary syndrome using different ethnic groups and populations. J Clin Endocrinol Metab, 11, 4361-8.

26. Spinelli A, Talamanca IF, Lauria L. (2000) Patterns of contraceptive use in 5 European countries. European Study Group on Infertility and Subfecundity. Am J Public Health, 9 , 1403-8.

27. Jones GL, Hall JM, Balen AH, et al. (2008) Health-related quality of life measurement in women with polycystic ovary syndrome: a systematic review. Hum Reprod Update, 1, 1525 . 
28. Schmid J, Kirchengast S, Vytiska-Binstorfer E, et al. (2004) Infertility caused by PCOS-health-related quality of life among Austrian and Moslem immigrant women in Austria. Hum Reprod, 10, 2251-7.

29. Weisberg E. (1985) Smoking and reproductive health. Clin Reprod Fertil, 3, 175-86.

30. Fuxe K, Andersson K, Eneroth P, et al. (1989) Neuroendocrine actions of nicotine and of exposure to cigarette smoke: medical implications. Psychoneuroendocrinology, 1-2, 19-41. 
Table 1: Geographic distribution of included patients $(n=1002)$

\begin{tabular}{|c|c|c|c|}
\hline Caucasian $(n=784)$ & Middle East $(\mathrm{n}=190)$ & Asian $(n=14)$ & Various $(n=14)$ \\
\hline Albania $(n=2)$ & Afghanistan $(n=4)$ & India $(\mathrm{n}=1)$ & African countries $(n=6)$ \\
\hline Armenia $(\mathrm{n}=1)$ & Arabia $(n=29)$ & Korea $(n=1)$ & South America $(n=3)$ \\
\hline Bosnia $(n=4)$ & $\operatorname{Iraq}(\mathrm{n}=36)$ & Sri Lanka $(\mathrm{n}=11)$ & Not noted $(\mathrm{n}=6)$ \\
\hline Croatia $(n=1)$ & $\operatorname{Iran}(\mathrm{n}=19)$ & $\operatorname{Vietnam}(\mathrm{n}=1)$ & \\
\hline Denmark $(n=765)$ & Jordan $(n=2)$ & & \\
\hline Poland $(n=3)$ & Lebanon $(n=12)$ & & \\
\hline Rumania $(n=1)$ & Pakistan $(\mathrm{n}=15)$ & & \\
\hline Russia ( $\mathrm{n}=1)$ & Palestine $(n=3)$ & & \\
\hline \multirow[t]{3}{*}{ Yugoslavia $(\mathrm{n}=6)$} & Syria $(n=2)$ & & \\
\hline & Turkey $(\mathrm{n}=57)$ & & \\
\hline & Middle east* $(n=11)$ & & \\
\hline
\end{tabular}

* Exact country not specified in patient reports. 
Table 2: Clinical and paraclinical data from patients divided according to ethnicity $(\mathrm{n}=974)$

\begin{tabular}{|c|c|c|}
\hline & $\begin{array}{c}\text { Caucasian } \\
(n=784)\end{array}$ & $\begin{array}{l}\text { Middle east } \\
\qquad(\mathrm{n}=190)\end{array}$ \\
\hline Age (years) & $32(25-37)^{* *}$ & $25(18-32)$ \\
\hline BMI $\left(\mathrm{kg} / \mathrm{m}^{2}\right)$ & $27.0(22.9-32.8)^{*}$ & $25.7(22.7-30.4)$ \\
\hline Waist (cm) & $90(78-104)^{* *} \S \S$ & $82(73-98)$ \\
\hline FG face & $4(2-5) * \S \S$ & $4(3-6)$ \\
\hline FG total & $11(7-15) * * \S \S$ & $16(11-22)$ \\
\hline T-testosterone (nmol/1) & $1.72(1.24-2.34) \S$ & $1.61(1.18-2.21)$ \\
\hline SHBG (nmol/1) & $47(33-70) * \S$ & $40(31-60)$ \\
\hline FTI & $0.031(0.020-0.047) \S$ & $0.030(0.019-0.048)$ \\
\hline DHEAS $(\mu \mathrm{mol} / \mathrm{l})$ & $5.8(4.1-8.1)^{*}$ & $6.3(4.7-9.2)$ \\
\hline Prolactin $(\mu \mathrm{g} / \mathrm{l})$ & $7(5-10)^{* *} \S \S$ & $9(6-12)$ \\
\hline Systolic BP (mmHg) & $127(117-138)^{* *} \S \S$ & $115(10-122)$ \\
\hline Diastolic BP (mmHg) & $80(72-89)^{* *} \S \S$ & $75(70-80)$ \\
\hline Cholesterol (mmol/l) & $4.8(4.2-5.5) * *$ & $4.4(3.9-5.0)$ \\
\hline $\mathrm{TG}(\mathrm{mmol} / \mathrm{l})$ & $1.1(0.8-1.6)^{*}$ & $0.9(0.7-1.4)$ \\
\hline HDL (mmol/l) & $1.4(1.1-1.7)$ & $1.4(1.1-1.7)$ \\
\hline LDL (mmol/l) & $2.8(2.2-3.5)^{* *}$ & $2.5(2.1-3.0)$ \\
\hline Fasting insulin (pmol/l) & $55(37-91)$ & $58(38-92)$ \\
\hline AUC insulin (pmol/l) & $3.8(2.4-6.6) * \S$ & $4.7(3.0-8.3)$ \\
\hline HOMA-r (pmol mmol 1-2) & $11.8(7.9-20.3)$ & $12.4(8.6-20.5)$ \\
\hline Fasting glucose (mmol/l) & $4.8(4.4-5.2)$ & $4.8(4.5-5.2)$ \\
\hline 2 h. glucose $(\mathrm{mmol} / \mathrm{l})$ & $6.0(5.1-7.1) \S$ & $6.1(5.2-7.2)$ \\
\hline Cortisol 0 (nmol/1) & $357(294-472)^{*}$ & $326(263-410)$ \\
\hline AUC cortisol (nmol/1) & $3.4(3.0-3.8)$ & $3.2(2.9-3.8)$ \\
\hline 17OHP 0 (nmol/1) & $4.1(2.9-6.2) \S$ & $4.0(2.8-5.7)$ \\
\hline AUC 17OHP (nmol/1) & $5.6(4.5-7.0)$ & $5.4(4.3-7.2)$ \\
\hline
\end{tabular}

Data presented as median (quartiles)

$*<0.05$ vs. ME patients

$* *<0.001$ vs. ME patients

$\S<0.05$ vs. ME patients after correcting for age and BMI

$\S \S<0.001$ vs. ME patients after correcting for age and BMI 
Table 3: Outcome of glucose tolerance tests

\begin{tabular}{lcc}
\hline & Caucasian & Middle east \\
\hline Normal glucose tolerance & $344 / 414=83.1 \%$ & $69 / 83=83.1 \%$ \\
IGT & $57 / 414=13.8 \%$ & $10 / 83=12.0 \%$ \\
Diabetes & $13 / 414=3.1 \%$ & $4 / 83=4.8 \%$ \\
Increased fasting insulin & $227 / 447=50.6 \% \S$ & $64 / 122=52.4 \%$ \\
\hline
\end{tabular}

$\S<0.05$ vs. ME patients after correcting for age and BMI

Glucose tolerance defined according to WHO criteria

Increased fasting insulin defined as $>55 \mathrm{pmol} / 1$ 
Table 4: Clinical and paraclinical data from patients with PCOS according to Rotterdam criteria $(\mathbf{n}=557)$.

\section{Caucasian}

$\mathrm{BMI} \leq 25 \mathrm{~kg} / \mathrm{m}^{2} \quad$ BMI $>25 \mathrm{~kg} / \mathrm{m}^{2}$

$(n=141)$

$(n=262)$

\begin{tabular}{|c|c|c|c|c|}
\hline & $\begin{array}{c}B M I \leq 25 \mathrm{~kg} / \mathrm{m}^{2} \\
(\mathrm{n}=141)\end{array}$ & $\begin{array}{c}\text { BMI }>25 \mathrm{~kg} / \mathrm{m}^{2} \\
(\mathrm{n}=262)\end{array}$ & $\begin{array}{c}B M I \leq 25 \mathrm{~kg} / \mathrm{m}^{2} \\
(\mathrm{n}=38)\end{array}$ & $\begin{array}{c}\text { BMI }>25 \mathrm{~kg} / \mathrm{m}^{2} \\
(\mathrm{n}=66)\end{array}$ \\
\hline Age (years) & $27(23-33)^{* * a 0}$ & $31(25-35)^{* *}$ & $22(17-27) \propto$ & $26(18-33)$ \\
\hline Waist $(\mathrm{cm})$ & $77(71-81) \times$ & $103(93-111)^{*}$ & $75(70-78) \propto$ & $98(87-106)$ \\
\hline FG face & $3(2-4) * \S \S \infty$ & $4(3-6) * \S \S$ & $4(3-6)$ & $5(3-6)$ \\
\hline FG total & $11(6-14)^{* * \S \S}$ & $11(7-16)^{* *} \S \S$ & $19(11-24)$ & $16(11-22)$ \\
\hline T-testosterone (nmol/1) & $1.89(1.34-2.31)$ & $2.02(1.43-2.73) \S$ & $1.59(1.12-2.23)$ & $1.82(1.31-2.47)$ \\
\hline SHBG (nmol/l) & $57(42-76)^{* * a}$ & $37(24-50)$ & $43(31-67) \mathfrak{a}$ & $33(22-49)$ \\
\hline FTI & $\begin{array}{c}0.030 \\
(0.019-0.045)\end{array}$ & $\begin{array}{c}0.043 \S \\
(0.028-0.062)\end{array}$ & $\begin{array}{c}0.028 \\
(0.019-0.043)\end{array}$ & $\begin{array}{c}0.044 \\
(0.022-0.057)\end{array}$ \\
\hline DHEAS $(\mu \mathrm{mol} / \mathrm{l})$ & $5.8(4.0-7.9)$ & $5.8(4.2-7.7)$ & $6.5(4.5-11)$ & $6.2(4.7-9.2)$ \\
\hline Prolactin $(\mu \mathrm{g} / \mathrm{l})$ & $7(4-10) \S$ & $7(5-10)^{*}$ & $11(7-15)$ & $8(6-11)$ \\
\hline Systolic BP (mmHg) & $120(110-132) * \infty$ & $129(120-140)^{* *} \S \S$ & $112(105-120)$ & $120(110-126)$ \\
\hline Diastolic BP (mmHg) & $73(69-81) a$ & $80(79-90)^{* *} \S \S$ & $70(68-80)$ & $75(70-80)$ \\
\hline Cholesterol (mmol/l) & $4.4(3.9-5.0)$ & $4.9(4.3-5.7)^{*} \S$ & $4.5(3.7-4.8)$ & $4.5(3.9-5.1)$ \\
\hline $\mathrm{TG}(\mathrm{mmol} / \mathrm{l})$ & $0.8(0.6-1.1) \mathrm{do}$ & $1.4(0.9-1.9)^{*}$ & $0.9(0.7-1.2)$ & $1.1(0.7-1.8)$ \\
\hline $\mathrm{HDL}(\mathrm{mmol} / \mathrm{l})$ & $1.6(1.3-1.8)$ & $1.2(1.0-1.4)$ & $1.5(1.3-1.7)$ & $1.2(1.0-1.5)$ \\
\hline LDL (mmol/l) & $2.5(2.0-2.9) \mathrm{do}$ & $3.0(2.4-3.7) * \S$ & $2.5(2.0-2.7)$ & $2.6(2.1-3.1)$ \\
\hline Fasting insulin (pmol/l) & $38(28-51)$ & $82(51-119)$ & $47(29-59) \mathrm{dod}$ & $77(49-105)$ \\
\hline AUCinsulin $\left(10^{4} \mathrm{pmol} / \mathrm{l}\right)$ & $2.8(1.7-3.5) * a$ & $5.3(3.2-8.3)$ & $3.6(2.7-7.4)$ & $6.0(3.7-8.9)$ \\
\hline HOMA (pmol mmol 1-2) & $8.5(5.6-11.1) \not$ & $17.1(10.8-27.8)$ & $10.0(6.7-14.4) \propto \alpha$ & $15.7(10.9-21.9)$ \\
\hline F. glucose $(\mathrm{mmol} / \mathrm{l})$ & $4.6(4.3-4.8)$ & $4.6(4.2-5.0)$ & $4.5(4.2-4.7)$ & $4.7(4.1-4.8)$ \\
\hline $2 \mathrm{~h}$. glucose $(\mathrm{mmol} / \mathrm{l})$ & $5.9(5.1-6.5) \propto$ & $6.3(5.1-7.4)$ & $6.0(4.9-6.9)$ & $6.4(5.4-7.6)$ \\
\hline
\end{tabular}

Data presented as median (quartiles). Data on BMI were not available in all cases.

$*<0.05$ vs. ME patients within BMI group

$* *<0.001$ vs. ME patients within BMI group

$\S<0.05$ vs. ME patients within BMI group after correcting for age

$\S \S<0.001$ vs. ME patients within BMI group after correcting for age

$\quad x<0.05$ vs. overweight individuals within ethnical group

od $<0.001$ vs. overveight individuals within ethnical group

Middle East

BMI $>25 \mathrm{~kg} / \mathrm{m}^{2}$ $(\mathrm{n}=66)$ 
Table 5. Regression analyses on the effect of ethnicity on hormonal and metabolic outcomes $(\mathbf{n}=974)$

\begin{tabular}{lcccc}
\hline $\begin{array}{c}\text { Log Dependent } \\
\text { variable }\end{array}$ & Log BMI & Log age & $\begin{array}{c}\text { Ethnicity } \\
\text { (Cau vs. ME) }\end{array}$ & $\mathbf{R}^{2}$ model \\
\hline T-testosterone & $0.21^{*}$ & $-0.32^{* *}$ & $-0.06^{*}$ & $0.04^{* *}$ \\
SHBG & $-1.09^{* *}$ & $0.22^{* *}$ & $-0.05^{*}$ & $0.17^{* *}$ \\
Free-testosterone & $0.82^{* *}$ & $-0.50^{* *}$ & $-0.06^{*}$ & $0.11^{* *}$ \\
Fasting insulin & $2.07^{* *}$ & $-0.46^{* *}$ & 0.002 & $0.47^{* *}$ \\
AUC insulin & $1.73^{* *}$ & $-0.31^{* *}$ & $0.084^{*}$ & $0.27^{* *}$ \\
HOMA & $2.18^{* *}$ & $-0.39^{* *}$ & 0.16 & $0.44^{* *}$ \\
F. glucose & $0.09^{*}$ & $0.085^{* *}$ & 0.003 & $0.05^{* *}$ \\
2 h. glucose & $0.37^{* *}$ & $0.10^{*}$ & $0.035^{*}$ & $0.09^{* *}$ \\
\hline
\end{tabular}

Multiple regression analyses were performed with metabolic outcomes as the dependent variables and ethnicity (cau=1, ME=2), BMI, and age as explanatory variables.

Metabolic outcomes, BMI, and age were log-transformed.

Data presented as B-value

$* \mathrm{p}<0.05$

$* * \mathrm{p}<0.001$ 
Figure 1. Metabolic risk profile and prevalence of individual Rotterdam criteria in CA vs. ME patients $(\mathbf{n}=974)$
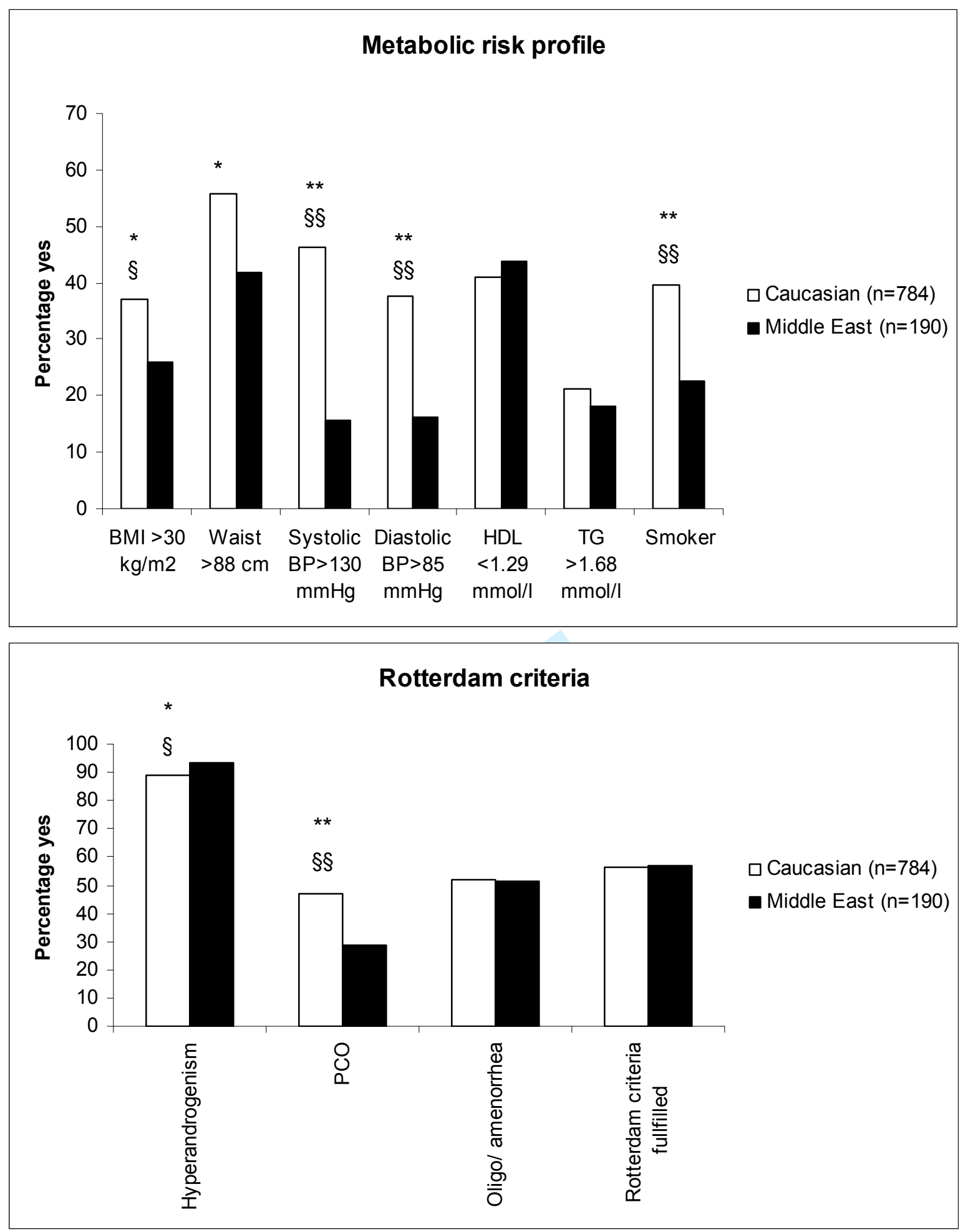

$*<0.05$ vs. ME patients 
$* *<0.001$ vs. ME patients

$\S<0.05$ vs. ME patients after correcting for age and BMI

$\S \S<0.001$ vs. ME patients after correcting for age and BMI 